\title{
Multivariate models to classify Tuscan virgin olive oils by zone
}

\author{
By Stefano Alessandri * ${ }^{1}$, Antonio Cimato ${ }^{2}$, Giuseppe Modi ${ }^{3}$, Angela Crescenzi ${ }^{4}$, \\ Simona Caselli ${ }^{5}$ and Stefania Tracchi ${ }^{3}$ \\ 1 Dipartimento di Ortoflorofrutticoltura Via G. Donizetti, 6 - 50144 Firenze, Italy. \\ E-mail: alessandri@agr.unifi.it \\ 2 Istituto per la Propagazione delle Specie Legnose - Firenze, Italy. \\ 3 ARPAT - Dipartimento Provinciale - Firenze, Italy. \\ 4 Dipartimento Agricoltura e Foreste - Regione Toscana - Firenze, Italy. \\ 5 Agronomo - Firenze, Italy.
}

\section{RESUMEN}

\section{Modelos multivariantes para clasificar aceites de oliva vírgenes Toscanos por zona.}

Para estudiar y clasificar aceites de oliva vírgenes Toscanos, se utilizaron 179 muestras, que fueron obtenidas de frutos recolectados durante la primera mitad de Noviembre, de tres zonas diferentes de la Región. El muestreo fue repetido durante 5 años. Se analizaron ácidos grasos, fitol, alcoholes alifáticos y triterpénicos, dialcoholes triterpénicos, esteroles, escualeno y tocoferoles. Se consideró un subconjunto de variables que fueron seleccionadas en un trabajo anterior como el más efectivo y fiable, desde el punto de vista univariado. Los datos analíticos se transformaron (excepto para el cicloartenol) para compensar las variaciones anuales, restándose la media de la zona Este de los demás valores, dentro de cada año. Se calcularon los modelos de tres clases univariados y además se desecharon variables. Posteriormente, se evaluaron modelos de tres zonas incluyendo fitol (que siempre fue seleccionado) y todas las combinaciones de ácidos palmítico, palmitoleico y oleico, tetracosanol, cicloartenol y escualeno. Se estudiaron modelos incluyendo desde dos a siete variables. El modelo mejor mostró errores de clasificación por zona inferiores al $40 \%$, errores de clasificación por zona dentro del año menores del $45 \%$ y errores de clasificación global igual al 30\%. Este modelo incluye fitol, ácido palmítico, tetracosanol y cicloartenol.

PALABRAS-CLAVE: Aceite de oliva virgen - Análisis discriminante - Modelo de clasificación - Toscana - Variables canónicas.

\section{SUMMARY}

Multivariate models to classify Tuscan virgin olive oils by zone.

In order to study and classify Tuscan virgin olive oils, 179 samples were collected. They were obtained from drupes harvested during the first half of November, from three different zones of the Region. The sampling was repeated for 5 years. Fatty acids, phytol aliphatic and triterpenic alcohols, triterpenic dialcohols, sterols, squalene and tocopherols were analyzed. A subset of variables was considered. They were selected in a preceding work as the most effective and reliable, from the univariate point of view. The analytical data were transformed (except for the cycloartenol) to compensate annual variations, the mean related to the East zone was subtracted from each value, within each year. Univariate three-class models were calculated and further variables discarded. Then multivariate three-zone models were evaluated, including phytol (that was always selected) and all the combinations of palmitic, palmitoleic and oleic acid, tetracosanol, cycloartenol and squalene. Models including from two to seven variables were studied. The best model shows by-zone classification errors less than $40 \%$, by-zone within-year classification errors that are less than $45 \%$ and a global classification error equal to $30 \%$. This model includes phytol, palmitic acid, tetracosanol and cycloartenol.

KEY-WORDS: Canonical variables - Classification model Discriminant analysis - Tuscany - Virgin olive oil.

\section{INTRODUCTION}

Tuscany is crossed by a virtual boundary: the northern limit of the cultivation area of Olea europaea.

Moreover, the Region shows a great eco-climatic variability, depending on its geographical position and on its complex orography (Maselli et al., 1996, Maracchi et al., 1994).

These two facts make the local production of virgin olive oil very diversified (Alessandri et al., 1997a). However it is extremely difficult to quantify these variations in absolute and reliable terms, because the related influences of the yearly variations of the climatic parameters appear very complex (Alessandri et al., 1997a, Alessandri 1993, Alessandri et al., 1997b). The annual variation of Tuscan olive oils quality can be greater than the variation due to the zone of origin (Alessandri et al., 1997a, Alessandri et al., 1997b). The same can be said for variations due to the harvesting time (Alessandri et al., 1995). Moreover, the interactions among all these factors (Alessandri et al., 1997a) give a difficult resolution to the problem.

Things become more difficult if olive oil characterization and classification is not only a scientific need but also an operational one, expecially if scientific findings have to be the basis for local, regional, national or european regulations.

This work is part of a group of researches to study, and eventually to try and resolve these 
problems. Multivariate classification models are discussed, with the aim of classifying Tuscan virgin olive oils by zone. The models are compensated for annual variations. The reliability and the discriminatory power of the variables considered here, was recently analyzed from the univariate point of view (Alessandri et al., 1997a). A multivariate model can show substantial increment of resolution, when compared to the performances of its univariate components.

\section{EXPERIMENTAL}

\subsection{Sampling and experimental design}

From the harvest season of $1989-90$ to $1993-94$ (labeled from «89» to «93» in figures and tables), 179 samples of virgin olive oil were collected. They were obtained exclusively from olives harvested in Tuscany during the first half of November.

In this paper, three zones of Tuscany are considered. The northern zone (labeled $\mathrm{N}$ in figures and tables), corresponds to Pistoia, Lucca, and Massa-Carrara. The Western zone (labeled W), covers the Tyrrhenian coast of Tuscany, without its extreme northern part, and extends over Livorno, and a portion of Grosseto. The inner part of Grosseto is included in the Eastern zone (labeled E) with Florence, Arezzo and Siena.

Data related to the $\mathrm{N}$ zone and to the 1991-92 harvest season are missing, due to lack of samples.

The descriptive statistics of the samples are reported elsewhere (Alessandri et al., 1997a).

\subsection{Chemical Analyses}

For each sample fatty acids, Phytol, aliphatic and triterpenic alcohols, triterpenic dialcohols, sterols, Squalene and tocopherols were determined.

Fatty acids were determined using the method stated by the Technical Commission of the Italian Agriculture Ministery (Commissione Tecnica 1976).

Phytol, aliphatic and triterpenic alcohols, triterpenic dialcohols, sterols and Squalene were determined as reported by Modi et al. (1991).

Tocopherols were determined by HPLC (RP-18 column, mm 250 length, mm 4,6 diameter; eluting phase of Acetonitrile, Methanol, Acetic Acid $2 \%$ water solution; detector UV 294 nm.; I.S. Tocopheril Acetate).

\subsection{Statistical Analysis}

All the calculations were made by means of the SAS package (Statistical Analysis System).

\subsubsection{Starting Variables}

Among the 34 variables derived from the chemical analyses (Alessandri et al. 1997a), only 10 were included in the classification models described in this paper: Palmitic, Palmitoleic and Oleic acid, Phytol Tetracosanol, Hexacosanol, Cycloartenol, Beta-Sitosterol, Delta-5-avenasterol, Squalene.

This first selection follows the assessment of their effectiveness and reliability, that was carried out by means of univariate (Alessandri et al., 1997a) and multivariate (Alessandri et al., 1997b) models. These models were calculated by zone-couples, within each year, on non-transformed data (see below). Data related to the harvest of the 1991-92 growing season were excluded from the calculation of the - models, but included in their testing.

\subsubsection{Compensation of yearly variations}

To compensate yearly variation the following steps were taken.

- Data were grouped by year.

- The East zone of Tuscany is the best known in terms of oils (and wines) of high quality and ancient tradition and it is the most studied (Alessandri et al., 1997a). Therefore the Eastzone was considered the reference zone. Within each year, all the data were transformed to make the mean of each variable related to the East-zone equal to zero.

- The Cycloartenol values were not transformed, because the "Year» is not a significant source of variation for this variable in Tuscany (Alessandri et al., 1997a).

- Each transformed variable was included in an ANOVA model (Analysis of variance) to confirm that, after the transformation, the "Year» was a not significant source of variation.

- If a variable did not match the condition above, it was discarded.

- The data related to the remaining variables were no more considered as grouped by year and were included in the following calculations as a whole. This approach made a substantial increase of the degrees of freedom of the classification models possible.

\subsubsection{Calculation of the classification models}

All the classification models were based on Linear Discriminant Analysis (Lachenbruch 1975, Hand 1981). They were cross-validated by the leavingone-out method (Lachenbruch and Mickey 1968) calculated on four-year data (see 3.3.1 and 3.3.2) and then tested on one-year data. 
The first calculations were made considering one couple of levels of the Zone variable (W vs. E, W vs. $\mathrm{N}$ and $\mathrm{E}$ vs. $\mathrm{N}$ ) at a time. Univariate models were calculated to verify their consistency with the models calculated by year, on non-transformed data (Alessandri et al., 1997a).

Then univariate and multivariate models were calculated, considering the three zones (E, N and W) together. In these models four years of data were included, but their classification errors were analyzed not only as a whole but also within each year (Table I). The variable selection was carried out, by means of the evaluation of all these errors. $50 \%$ and $45 \%$ of misclassified observations were adopted as selecting thresholds, to evaluate the following:

- The total discriminatory power (total of misclassified observations)

- The capability to recognize the three zones at the same level (observations misclassified byzone, considering all the years together, except for 1991)

- The yearly consistency (within-year misclassified observations, i.e. total of misclassified observations from the three zones of each single year).

\section{RESULTS AND DISCUSSION}

\subsection{ANOVA}

After the transformation described above, the "Year" is not a significant source of variation for any of the 10 variables that were investigated at first (ANOVA calculations not reported). The «Zone», on the contrary, is always highly significant.

\subsection{Classification models}

The univariate models, calculated by zonecouples (Table I), confirm the results derived from models calculated by year on original values (Alessandri et al., 1997a). Oleic Acid and Phytol score low classification errors for three zonecouples. Palmitic, Palmitoleic acid, and Tetracosanol effectively classify the Western observations vs the others. Hexacosanol and Squalene effectively classify the Eastern oils vs the Western and the Northern.

Table I

Classification errors of the univariate classification models

\begin{tabular}{|c|c|c|c|c|c|c|c|c|c|c|c|c|c|c|c|c|}
\hline \multirow{3}{*}{ Analysis Variable } & \multicolumn{16}{|c|}{ Classification errors (percent) } \\
\hline & & \multicolumn{7}{|c|}{$\begin{array}{l}\text { Four year two-class } \\
\text { cross-validated models }\end{array}$} & \multicolumn{3}{|c|}{$\begin{array}{l}\text { Four year three-class } \\
\text { cross-validated models }\end{array}$} & \multicolumn{5}{|c|}{$\begin{array}{l}\text { Four year three-class mod.: } \\
\text { TEST on one-year sub-set of data }\end{array}$} \\
\hline & & E & & $W$ & E & $\mathbf{N}$ & $\mathbf{N}$ & W & $\mathbf{E}$ & $\mathbf{N}$ & W & 89 & 90 & (91) & 92 & 93 \\
\hline Palmitic Acid & & 18 & & 22 & 40 & 36 & 27 & 30 & 40 & $\frac{64}{15}$ & 30 & 35 & 51 & (47) & 35 & $\underline{55}$ \\
\hline & Total & & 20 & & & & & & & 45 & & & & & & \\
\hline Palmitoleic Acid & Total & 19 & 23 & 26 & 33 & 45 & 27 & 35 & 33 & $\frac{73}{47}$ & 35 & $\underline{57}$ & 39 & $(\underline{48)}$ & 45 & 40 \\
\hline Oleic Acid & Total & 18 & 22 & 26 & $\underline{36}$ & 32 & 27 & 30 & 36 & $\frac{59}{42}$ & 30 & 56 & $\underline{52}$ & $(\underline{55})$ & 33 & 36 \\
\hline Tetracosanol & Total & 19 & 25 & 30 & $\underline{39}$ & 43 & 24 & 30 & 39 & $\frac{67}{45}$ & 30 & 41 & 53 & (47) & 46 & 44 \\
\hline Hexacosanol & Total & 31 & 35 & $\underline{39}$ & 37 & 29 & 52 & 48 & 37 & $\underline{\underline{81}}$ & 48 & $\underline{\underline{54}}$ & $\underline{58}$ & $(\underline{\underline{58}})$ & $\underline{65}$ & $\underline{\underline{51}}$ \\
\hline Phytol & Total & 11 & 20 & 30 & 19 & 33 & 29 & 43 & 19 & $\frac{62}{41}$ & 43 & $\underline{56}$ & 46 & (44) & 15 & 38 \\
\hline Cycloartenol & Total & 39 & 35 & 30 & 26 & 29 & 38 & 39 & 39 & $\begin{array}{l}38 \\
49\end{array}$ & 70 & 67 & 45 & $(\underline{73})$ & 38 & $\underline{62}$ \\
\hline Beta-Sitosterol & Total & 38 & 41 & 43 & 31 & 33 & 43 & 43 & 38 & $\begin{array}{l}43 \\
56 \\
\end{array}$ & 87 & 49 & $\underline{\underline{55}}$ & (64) & $\underline{55}$ & $\underline{\underline{65}}$ \\
\hline Delta-5-avenasterol & Total & 33 & 38 & 43 & 31 & 24 & 48 & 52 & 33 & $\begin{array}{l}48 \\
59 \\
\end{array}$ & 96 & 61 & $\underline{54}$ & (67) & 59 & 65 \\
\hline Squalene & Total & 35 & 33 & 30 & 26 & 24 & 43 & 43 & 35 & $\begin{array}{l}43 \\
51 \\
\end{array}$ & 74 & 64 & 52 & (65) & 48 & 48 \\
\hline & Mean & & & & & & & & & & & 54 & 51 & (57) & 44 & 50 \\
\hline
\end{tabular}

Percent of misclassified observations related to the zones or the years listed below. The data from the 1991-92 harvesting season (Year=91) are not included in all the calculations.

In two-class classification models, the errors greater than $35 \%$ are underlined.

In three-class classification models, the errors greater than $45 \%$ are underlined and the errors greater than $50 \%$ are double-underlined

All the variables except for Cycloartenol have been transformed (see text). 
The three-zone univariate models (Table I) show total classification errors between $41 \%$ and $59 \%$. Oleic Acid and Phytol score the lowest errors $(42 \%$ and $41 \%)$, while Delta-5-Avenasterol (59\%) e BetaSitosterol (56\%), the highest.

If we consider the within-year classification errors (excluding 1991), it can be noted that Palmitoleic acid, Tetracosanol and Phytol show only one value greater than $50 \%$. Hexacosanol, Beta-Sitosterol and
Delta-5-Avenasterol, on the other side, show three or four values greater than that threshold.

For these reasons Phytol was selected to be included in all the multivariate models, and Beta-Sitosterol, Delta-5-Avenasterol and Hexacosanol were discarded. Therefore the subsequent multivariate models were calculated including all the 63 simple combinations of Phytol and six variables: Palmitic, Palmitoleic and Oleic acid, Tetracosanol, Cycloartenol and Squalene (Tables Ila and Illb).

Table lla

Classification errors of the multivariate classification models

\begin{tabular}{|c|c|c|c|c|c|c|c|c|c|c|c|c|c|c|}
\hline \multirow{3}{*}{$\begin{array}{c}\text { First } \\
\text { Analysis } \\
\text { Variable }\end{array}$} & \multirow{3}{*}{$\begin{array}{l}\text { Second } \\
\text { Analysis } \\
\text { Variable }\end{array}$} & \multirow{3}{*}{$\begin{array}{l}\text { Third } \\
\text { Analysis } \\
\text { Variable }\end{array}$} & \multirow{3}{*}{$\begin{array}{l}\text { Fourth } \\
\text { Analysis } \\
\text { Variable }\end{array}$} & \multirow{3}{*}{$\begin{array}{c}\text { Fifth } \\
\text { Analysis } \\
\text { Variable }\end{array}$} & \multirow{3}{*}{$\begin{array}{c}\text { Sixth } \\
\text { Analysis } \\
\text { Variable }\end{array}$} & \multicolumn{9}{|c|}{ Classification errors (percent) } \\
\hline & & & & & & \multicolumn{4}{|c|}{$\begin{array}{l}\text { Four-year three-class } \\
\text { cross-valid. models }\end{array}$} & \multicolumn{5}{|c|}{$\begin{array}{l}\text { Four-year three-class mod.: } \\
\text { TEST on one-year sub-set of data }\end{array}$} \\
\hline & & & & & & $E$ & $\mathbf{N}$ & $w$ & Total & 89 & 90 & (91) & 92 & 93 \\
\hline Phytol & & & & & & 19 & $\underline{62}$ & 43 & 41 & $\underline{\underline{56}}$ & 46 & (44) & 15 & 38 \\
\hline Phytol & Palmitic Acid & & & & & 26 & $\underline{\underline{62}}$ & 39 & 42 & $\underline{\underline{53}}$ & 34 & (33) & 34 & $\underline{50}$ \\
\hline Phytol & Palmitol. Acid & & & & & 26 & $\underline{\underline{62}}$ & 43 & 44 & $\underline{\underline{56}}$ & 44 & (38) & 24 & 49 \\
\hline Phytol & Oleic Acid & & & & & 24 & $\underline{52}$ & 35 & 37 & $\underline{\underline{65}}$ & 38 & (44) & 16 & 28 \\
\hline Phytol & Tetracos. & & & & & 18 & $\underline{71}$ & 48 & 46 & $\underline{\underline{63}}$ & 46 & (38) & 16 & 50 \\
\hline Phytol & Cycloart. & & & & & 19 & 43 & 48 & 36 & $\underline{53}$ & 39 & (41) & 27 & 30 \\
\hline Phytol & Squalene & & & & & 23 & 38 & 52 & 38 & 36 & 37 & (46) & 32 & 40 \\
\hline Phytol & Palmitic Acid & Palmitol. Acid & & & & 29 & 57 & 35 & 41 & $\underline{53}$ & 34 & (33) & 25 & $\underline{\underline{51}}$ \\
\hline Phytol & Palmitic Acid & Oleic Acid & & & & 26 & 48 & 35 & 36 & $\underline{70}$ & 38 & (44) & 15 & 32 \\
\hline Phytol & Palmitic Acid & Tetracos. & & & & 23 & 62 & 39 & 41 & $\underline{55}$ & 38 & (32) & 23 & 50 \\
\hline Phytol & Palmitic Acid & Cycloart. & & & & 22 & 38 & 39 & 33 & 44 & 26 & (35) & 23 & 38 \\
\hline Phytol & Palmitic Acid & Squalene & & & & 29 & 43 & 48 & 40 & 40 & 39 & (33) & 29 & 43 \\
\hline Phytol & Palmitol. Acid & Oleic Acid & & & & 27 & $\underline{57}$ & 35 & 40 & $\underline{56}$ & 28 & (38) & 26 & 39 \\
\hline Phytol & Palmitol. Acid & Tetracos. & & & & 24 & $\underline{71}$ & 30 & 42 & $\underline{\underline{55}}$ & 32 & (38) & 23 & $\underline{\underline{54}}$ \\
\hline Phytol & Palmitol. Acid & Cycloart. & & & & 23 & 38 & 39 & 33 & $\underline{\underline{53}}$ & 31 & (46) & 12 & 44 \\
\hline Phytol & Palmitol. Acid & Squalene & & & & 26 & 43 & 39 & 36 & 41 & 22 & (30) & 26 & 47 \\
\hline Phytol & Oleic Acid & Tetracos. & & & & 23 & $\underline{57}$ & 48 & 43 & $\underline{\underline{63}}$ & 37 & (44) & 24 & 36 \\
\hline Phytol & Oleic Acid & Cycloart. & & & & 19 & 33 & 35 & 29 & $\underline{61}$ & 36 & (46) & 11 & 23 \\
\hline Phytol & Oleic Acid & Squalene & & & & 29 & 38 & 35 & 34 & $\underline{\underline{51}}$ & 29 & (38) & 26 & 30 \\
\hline Phytol & Tetracos. & Cycloart. & & & & 17 & 48 & 43 & 36 & $\underline{\underline{53}}$ & 45 & (44) & 03 & 40 \\
\hline Phytol & Tetracos. & Squalene & & & & 26 & 43 & 43 & 38 & 33 & 37 & (38) & 26 & 45 \\
\hline Phytol & Cycloart. & Squalene & & & & 23 & 48 & 49 & 40 & 49 & 37 & (43) & 30 & 30 \\
\hline Phytol & Palmitic Acid & Palmitol. Acid & Oleic Acid & & & 28 & 57 & 35 & 40 & $\underline{55}$ & 32 & (38) & 15 & 43 \\
\hline Phytol & Palmitic Acid & Palmitol. Acid & Tetracos. & & & 25 & 67 & 30 & 41 & $\underline{55}$ & 28 & (44) & 23 & 50 \\
\hline Phytol & Palmitic Acid & Palmitol. Acid & Cycloart. & & & 25 & 43 & 30 & 33 & 44 & 31 & (41) & 15 & 47 \\
\hline Phytol & Palmitic Acid & Palmitol. Acid & Squalene & & & 28 & 48 & 35 & 37 & 33 & 17 & (24) & 29 & 50 \\
\hline Phytol & Palmitic Acid & Oleic Acid & Tetracos. & & & 25 & 62 & 48 & 45 & $\underline{68}$ & 35 & (44) & 24 & 40 \\
\hline Phytol & Palmitic Acid & Oleic Acid & Cycloart. & & & 21 & 33 & 35 & 30 & 61 & 36 & (46) & 11 & 23 \\
\hline Phytol & Palmitic Acid & Oleic Acid & Squalene & & & 27 & 38 & 39 & 35 & 45 & 29 & (36) & 26 & 30 \\
\hline Phytol & Palmitic Acid & Tetracos. & Cycloart. & & & 18 & 33 & 39 & 30 & 44 & 31 & (38) & 10 & 38 \\
\hline Phytol & Palmitic Acid. & Tetracos. & Squalene & & & 25 & 43 & 39 & 36 & 28 & 32 & (38) & 27 & $\underline{\underline{51}}$ \\
\hline Phytol & Palmitic Acid & Cycloart. & Squalene & & & 28 & 38 & 43 & 37 & 44 & 33 & $(38)$ & 24 & 38 \\
\hline
\end{tabular}

Percent of misclassified observations related to the zones or the years listed below. The data from the 1991-92 harvesting season (Year $=91)$ are not included in all the calculations.

Errors greater than $45 \%$ are underlined. Errors greater than $50 \%$ are double-underlined.

For the sake of comparison also the errors related to the Phytol univariate model are reported. 
Table Ilb

Classification errors of the multivariate classification models

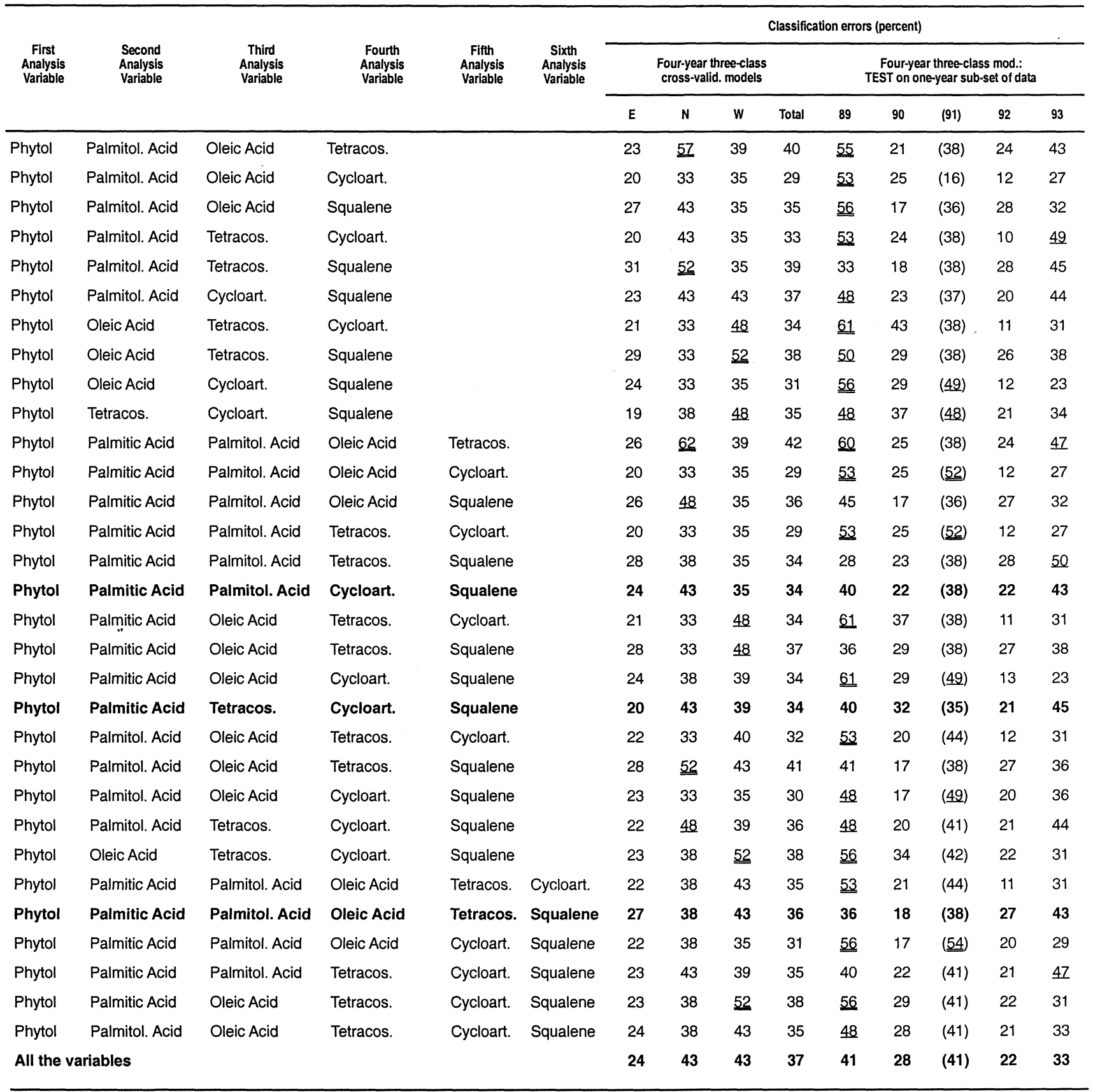

Percent of misclassified observations related to the zones or the years listed below. The data from the 1991-92 harvesting season $($ Year $=91)$ are not included in all the calculations.

Errors greater than $45 \%$ are underlined. Errors greater than $50 \%$ are double-underlined.

For the sake of comparison also the errors related to the Phytol univariate model are reported. All the variables except for Cycloartenol, have been transformed (see text).

Bivariate models (Table Ila) show that the inclusion of Cycloartenol or Oleic Acid, or Squalene, decreases the total classification error from $41 \%$ (Phytol-only model) to the corresponding $36 \%, 37 \%$ and $38 \%$. The by-zone classification errors of the Phytol+Cycloartenol model are all less than $50 \%$. The same can be said about the within-year errors related to the Phytol+Squalene model. 
Among the 15 models of three dimensions (Tab. Ila), four lead to a further decrement of the total misclassified observations. Three of them include Cycloartenol and Palmitic, or Palmitoleic, or Oleic Acid. They respectively show errors of $33 \%, 33 \%$, $29 \%$. The fourth model includes Oleic Acid and Squalene and scores $34 \%$ of total classification error. The by-zone classification errors and the within-year errors related to the Phytol+PalmiticAcid+Cycloartenol model are both less than $45 \%$. This particular feature and its effectiveness, both make this the most interesting three-dimension model. It correctly recognizes all the three zones and shows a remarkable stability through the years. This is not the case of the Phytol+Oleic acid+Cycloartenol model. For this reason it was considered less valuable, though it scores a lower total classification error (29\%).

Among the 20 models of four dimensions (Tables lla and IIIb), only the Phytol+Palmitic Acid+Tetracosanol+ Cycloartenol model shows the features emphasized above (Figures 1-5), and a further reduction of the total classification error from $33 \%$ (Phytol+Palmitic Acid+Cycloartenol model) to $30 \%$.

Two of the 15 models of five dimensions show within-year errors that match the $45 \%$ threshold. Both include Phytol, Palmitic Acid, Cycloartenol and Squalene. The fifth variable is Palmitoleic Acid or Tetracosanol. Both perform worse than the formerly selected models and misclassify $34 \%$ of the observations.

This trend is shared by the only six-variable model related to by-zone and within-year errors matching the $45 \%$ threshold. It includes Phytol, Palmitic, Palmitoleic, Oleic Acid, Tetracosanol and Squalene, and misclassifies $36 \%$ of observations. The same trend is confirmed by the inclusion of the last variable: the seven-dimension model matches the $45 \%$ thresholds as above, but misclassifies a further $1 \%$ of observations (total classification error $37 \%$ ).

The items discussed till now can be summarized looking at the performances of the models selected within each number of variables (Table III).

Years 1989-93

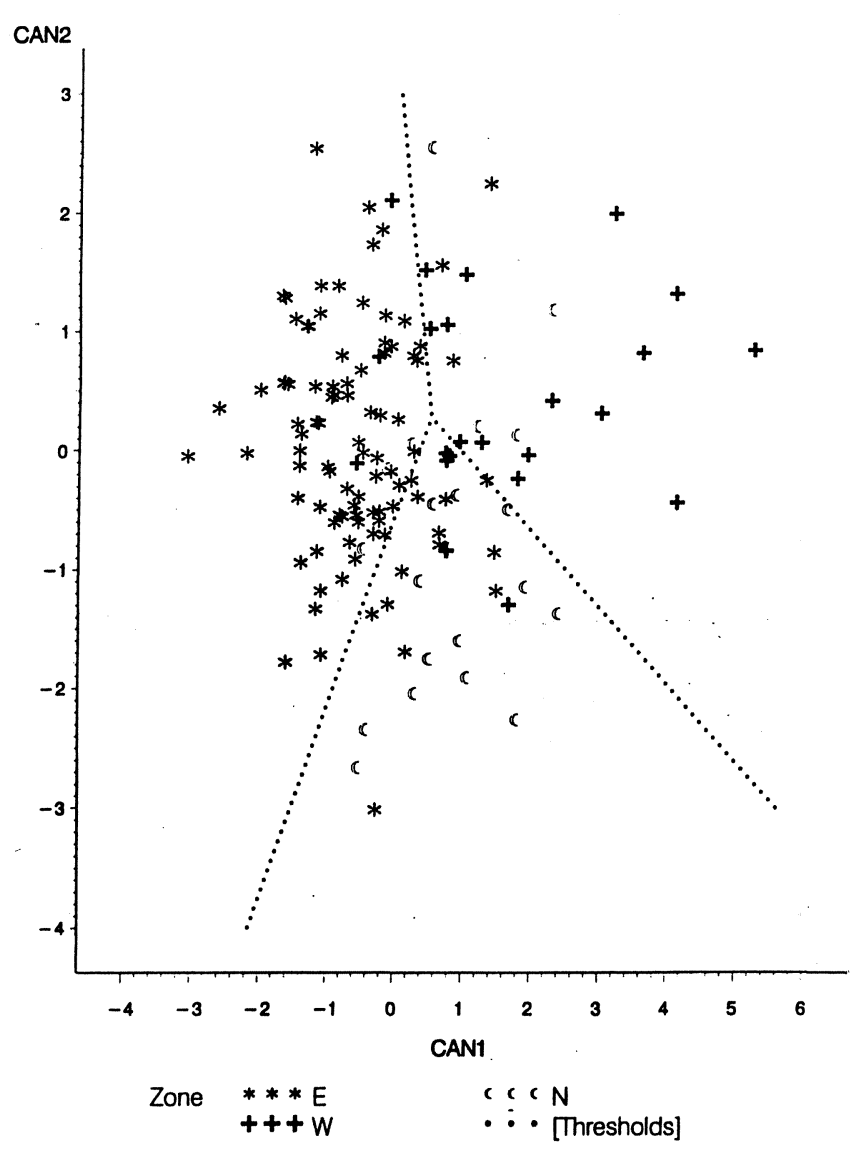

Figure 1

Distribution of the observations in the space of the canonical variates (CAN1 and CAN2). Observations from the Eastern, Northern and Western zones of Tuscany are labeled "E», "N" and "W" respectively. The dotted lines correspond to the between-zone threshold. These are derived from the linear discriminant function including the two canonical variates.

CAN 1 and CAN2 are linear combinations of the transformed (see text) values of Phytol, Palmitic Acid, Tetracosanol, Cycloartenol.

The classification model including these variables is the most effective and reliable, among the models considered $i$ this work.

Olive oils extracted from drupes harvested during the seasons of 1989-90, 1990-91, 1992-93 and 1993-94 are represented. 
Vol. 50. Fasc. 5 (1999)

Year 1989

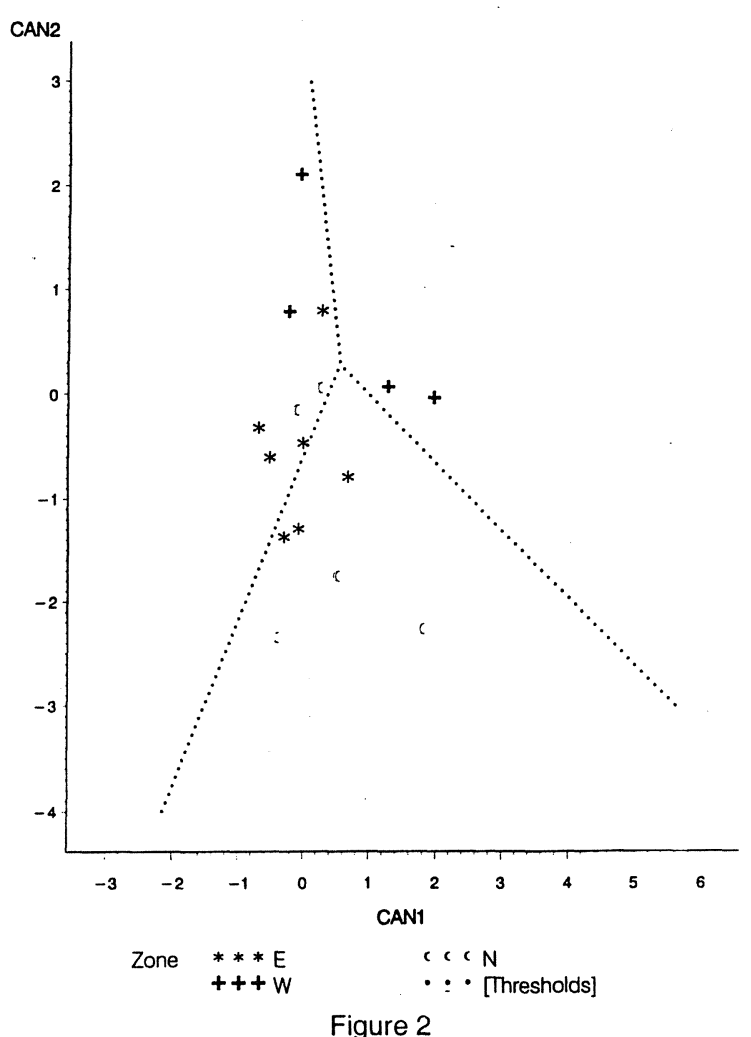

The same classification model as in Figure 1 is shown here, but only Tuscan Olive oils extracted from drupes harvested during 1989-90 are displayed

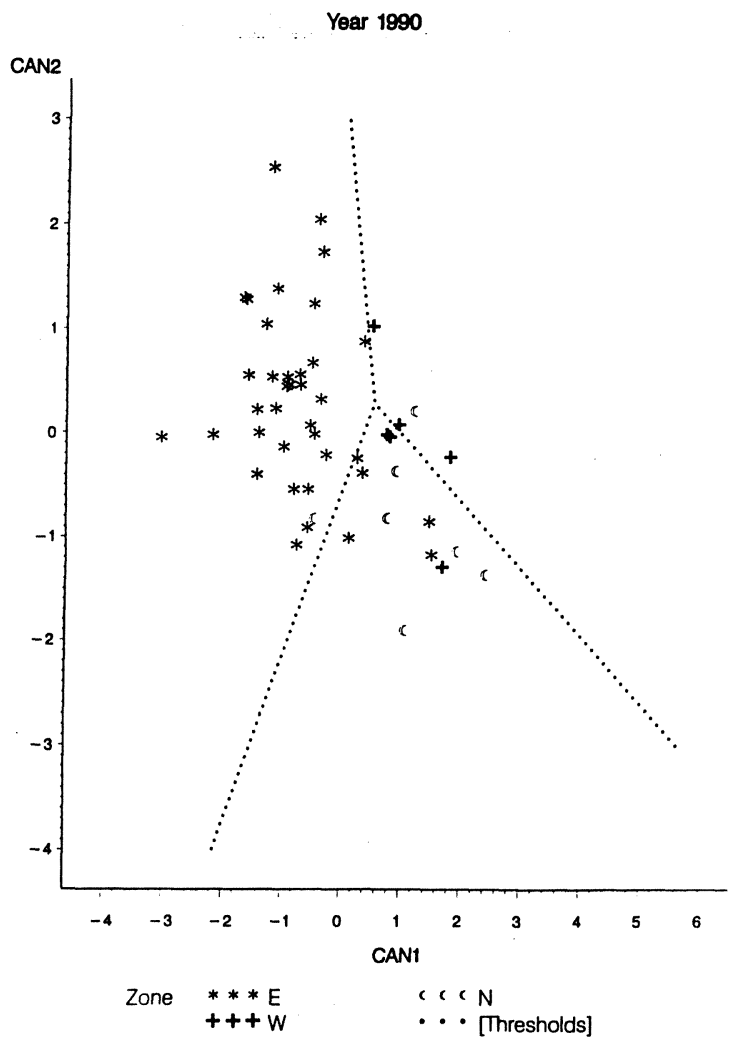

Figure 3

The same classification model as in Figure 1 is shown here, but only Tuscan Olive oils extracted from drupes harvested during 1990-91 are displayed 
Year 1992

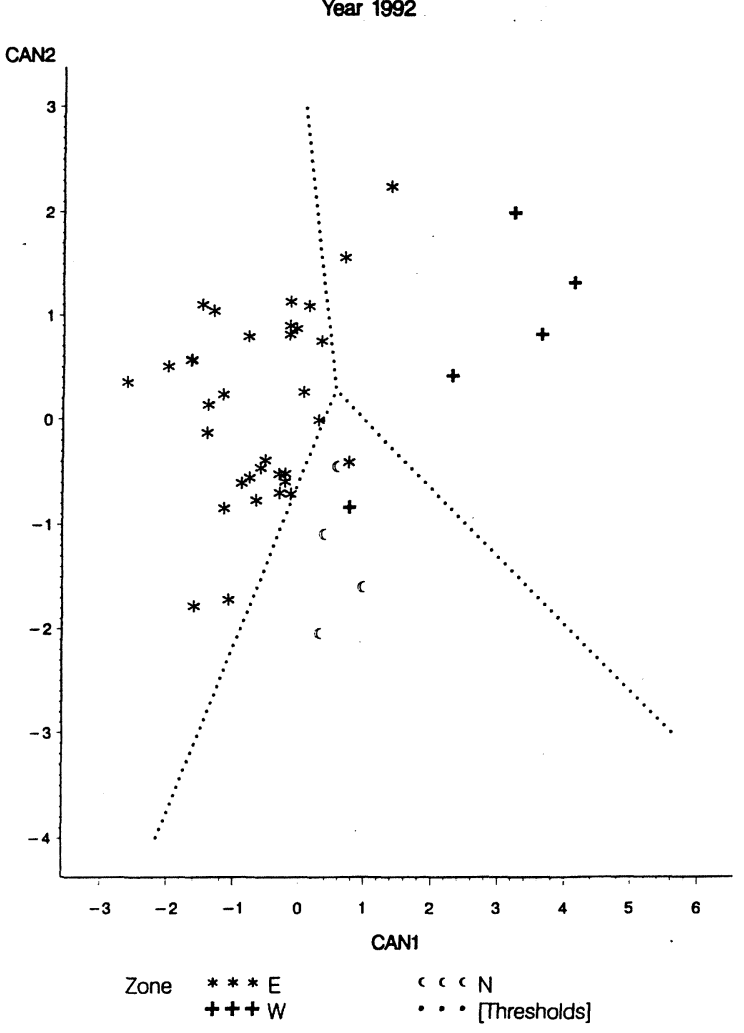

Figure 4

The same classification model as in Figure 1 is shown here, but only Tuscan Olive oils extracted from drupes harvested during 1992-93 are displayed

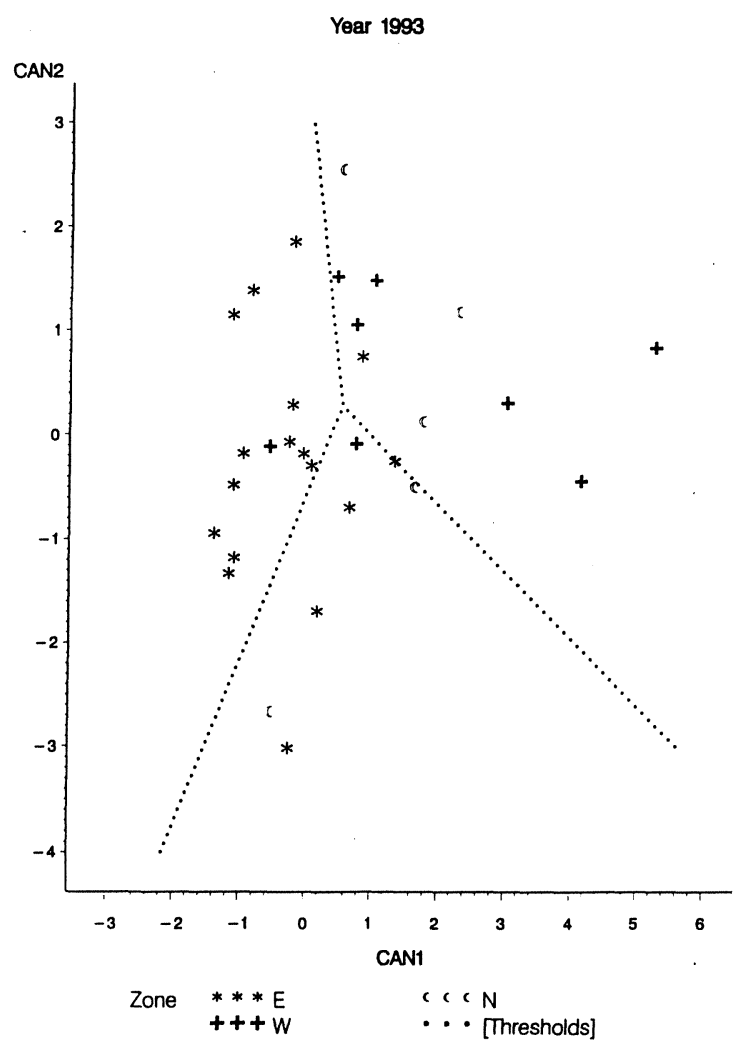

Figure 5

The same classification model as in Figure 1 is shown here, but only Tuscan Olive oils extracted from drupes harvested during 1993-94 are displayed 
Table III

Classification errors of the best classification models

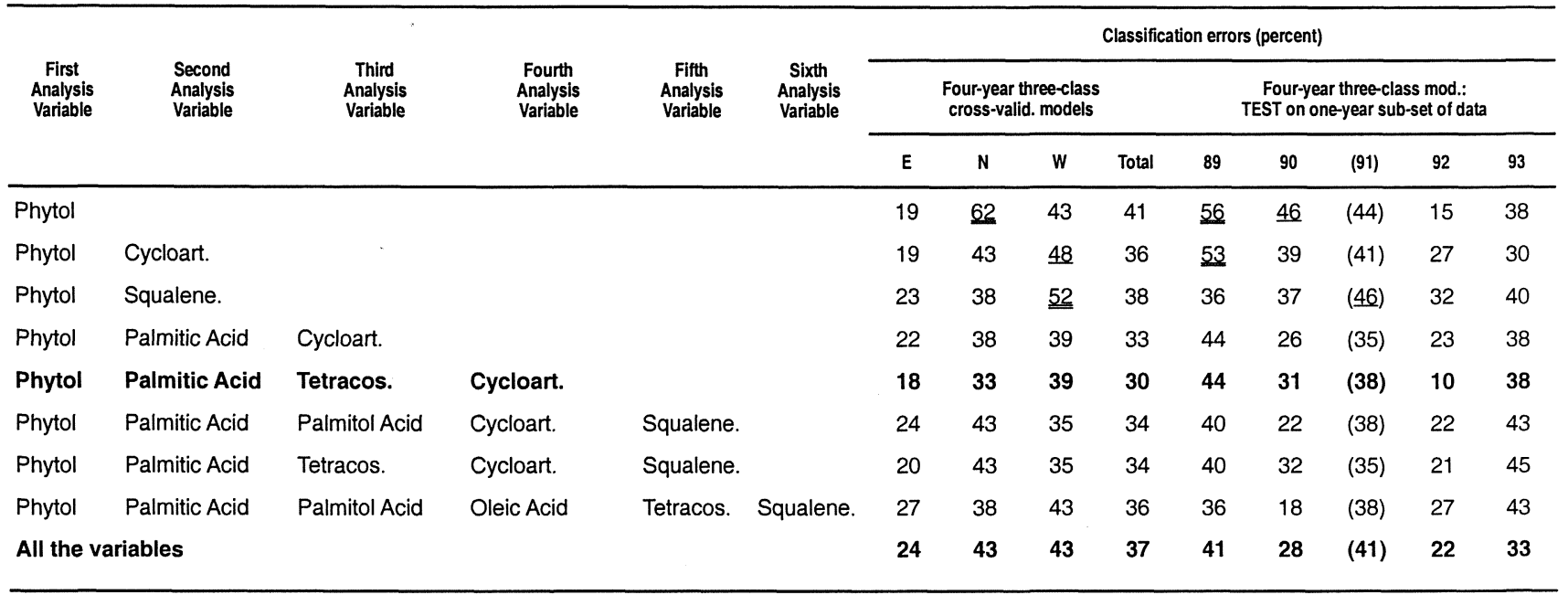

Percent of misclassified observations related to the zones or the years listed below. The data from the 1991-92 harvesting season (Year $=91)$ are not included in all the calculations.

Errors greater than $45 \%$ are underlined. Errors greater than $50 \%$ are double-underlined

For the sake of comparison also the errors related to the Phytol univariate model are reported.

All the variables except for Cycloartenol, have been transformed (see text)

Among these nine models only one shows the lowest total classification error of $30 \%$. It is the four-dimension model including: Phytol, Palmitic Acid, Tetracosanol, and Cycloartenol (Table IV, Figure 1-5). It shows a remarkable feature: all its by-zone classification errors are less than $40 \%$ (Table III, Figure 1). This characteristic is shared by the selected three-dimension model (Phytol+Palmitic Acid+ Cycloartenol), but this model shows a higher total classification error (33\%, Table III). The bi-dimensional representation of the selected four-dimension model (Figures 1-5) was obtained by means of the two related canonical variates. The discriminant linear function and its classifying thresholds were then re-calculated from the canonical variates. The selected four-dimension model was also re-calculated including the non-transformed variables. It is worth underlining that the related total classification error rises to $39 \%(+9 \%)$. This confirms the importance of taking account of yearly variations.

Table IV

Multivariate classification model including Phytol, Palmitic Acid, Tetracosanol, Cycloartenol: Linear Discriminant Function

\begin{tabular}{llccc}
\hline \multicolumn{1}{c}{ Constant $=-.5 \overline{\mathrm{x}}_{\mathrm{j}} \mathrm{COV}^{-1} \overline{\mathrm{x}}_{\mathrm{j}}$} & Coefficient Vector $=\mathrm{COV}^{-1} \overline{\mathrm{x}}_{\mathrm{j}}$ & \\
\multicolumn{1}{c}{ Zone } & & $\mathrm{E}$ & $\mathrm{N}$ & $\mathrm{W}$ \\
CONSTANT & & -12.76260 & -7.59981 & -11.09198 \\
Phytol & $(\mathrm{mg} / \mathrm{kg})$ & 0.12775 & 0.25739 & 0.29154 \\
Palmitic Acid & $(\%$ chrom. area $)$ & -1.15294 & -1.02032 & 0.05379 \\
Tetracosanol & $(\%$ chrom. area $)$ & -0.07990 & -0.01367 & 0.12611 \\
Cycloartenol & $(\%$ chrom. area $)$ & 0.68900 & 0.51221 & 0.57362 \\
\hline
\end{tabular}

All the variables except for Cycloartenol have been transformed (see text). 
Some results (Table III) reported in this paper can be compared to those regarding univariate models calculated by zone-couples, a year at a time and on original values (3). The two groups of the best performing variables have remarkable overlappings:

- Phytol had been formerly selected to classify Eastern vs Westem and Northern Tuscan olive oils;

- Palmitoleic and Oleic Acid had been formerly selected to classify Western vs Eastern and Northern observations;

- Cycloartenol had been formerly selected to classify Northern vs Eastern and Western oils both in univariate (Alessandri et al., 1997a) and multivariate (Alessandri et al., 1997b) models.

\section{CONCLUSIONS}

Multivariate effective and reliable models can be calculated, to classify virgin olive oils from Tuscany, on a three-zone basis.

It is important to compensate analytical values for the yearly variations. The method presented here requires either the harvesting year of a blind sample to be known or, for the same year, a reference sampling (the East-zone), to estimate and compensate the variation related to that year.

According to our data, Phytol, Palmitic, Palmitoleic and Oleic acid, Tetracosanol, Cycloartenol and Squalene are related to effectiveness and reliability.

Models including phytol, palmitic acid, cycloartenol with or without tetracosanol misclassify $30 \%$ or $33 \%$ of the observations. They are related to by-zone classification errors lower than $40 \%$ and to withinyear classification errors lower than $45 \%$.

\section{ACKNOWLEDGEMENTS}

The authors thank the C.R.O.E.V.O.T.T. (Consorzio Regionale Olio Extra Vergine di Oliva Tipico Toscano), the I.V.O.T. (Istituto Vino e Olio di Toscana), the Regione Toscana and all the olive cultivators whose work made this research possible.
The authors are grateful to Marina Spinelli Dondoli for her assistance in editing the text.

\section{BIBLIOGRAPHY}

Alessandri, S. (1993)._- «Variabilitá annuale e cambiamenti legati al periodo di raccolta delle drupe, nella composizione chimica degli oli toscani».Proceedings of Presentazione dei resultati delle ricerche inerenti alla caratterizzazione dell'olio extra-vergine di Toscana. Attivitá 1991-92e sviluppi futuri. Appendice. Firenze (Italy) Oct. 19, 1993.

Alessandri, S., Caselli, S., Crescenzi, A., Tracchi, S. (1995). - «Modelli chemiometrici per la classificazione degli oli di oliva in base a cultivar, zona di coltivazione, periodo di raccolta delle drupe».-Bollettino dei Chimici Igienisti parte scientifica, 46, 405-416.

Alessandri, S.. Cimato, A., Modi, G., Mattei, A., Crescenzi, A., Caselli, S., Tracchi, S. (1997a)._-Univariate models to classify Tuscan virgin olive oils by zone».-La Rivista Italiana delle Sostanze Grasse, 74, 155-164.

Alessandri, S., Cimato, A., Caselli, S., Baldini, A., Crescenzi, A., Modi, G., Tracchi, S. (1997b).- - The characterization and classification of Tuscan olive oils by zone: yearly variations of the oil composition and reliability of the classification models".-Third International Symposium on Olive Growing, Chania, Greece, 22-26 September, 1997.

Commissione Tecnica Governativa per gli oli minerali, i grassi, i colori, le vernici e i detersivi. (1976).—«Norme italiane per il controllo dei grassi e derivati».Ministero dell' Industria Roma.

Hand, D. J. (1981).—-Discriminations and classification».Wiley, New York.

Lachenbruch, P. A. (1975).-—Discriminant analysis».Hafner Press, New York.

Lachenbruch, P. A., Mickey, M. R. (1968).- «Estimation of error rates in discriminant analysis".-Technometrics, 10, 1-11.

Maracchi, G., Pittalis, F., Bindi, M., Sillari, B. (1994)."Olive production e meteorological factors: a preliminary study".-Olivae, 52.

Maselli, F., Petkov, L., Maracchi, G., Conese, C. (1996).«Eco-climatic classification of Tuscany through NOAA-AVHRR data».-International Journal of Remote Sensing, 17 (12) 2369-2384.

Modi, G., Fabbrini, A., Simiani, G., Tracchi, S., Mattei, A., Cimato, A. (1991).—-Studio di componenti della frazione insaponificabile di oli toscani ottenuti da varie cultivar".-Bollettino dei Chimici Igienisti, 42, 787-801. 